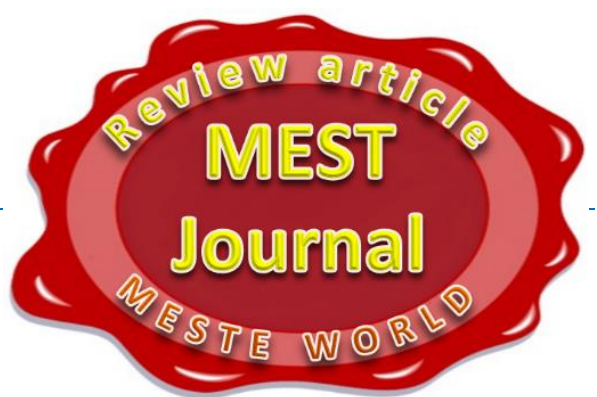

\title{
EUROPEAN MARKETING - CONCEPT FOR EFFICIENT EXCHANGE OF THE SINGLE MARKET OF THE EUROPEAN UNION
}

\author{
Viera Čihovská \\ School of Economics and Management in Public Administration in Bratislava, Slovakia
}

\author{
(C) MESTE NGO
}

JELcategory: J11, A14

\begin{abstract}
The scale of economic and political integration of the European Union is unprecedented within the whole history of mankind and in many areas it exceeded the level of cooperation between territorial communities and some free federations. European Union gives the current configuration of European countries, modern and sustained nature. By the emergence and gradual enlargement of the EU is formed the common market, which forms a strong economic area without internal frontiers with the free movement of goods, persons, services and capital. Currently market represents $40 \%$ of world trade and it is the largest internal market with fixed terms applied to all EU countries. It is alliance of 27 states, with their own traditions, manners, languages, culture and religion, into a multinational unit where the country differences intersected. Common market requires a specific marketing approach and the concept must take into account changeable market conditions, depending on country where we do business.

In present time European Union includes many different countries, which are difference in economy development, size, cultural, tongues, religion, habits and history. The main aim of EU is to make up economy and currency union, which is development, competitive ability and could be successful in the global economy. The important task of the integration is to support competitive ability of all member countries and its companies and creating the common market, where can be European marketing helpful in this case.
\end{abstract}

Keywords: European Union, European marketing, marketing conception, global marketing, intercultural marketing, segmentation, convergence, divergence

\section{INTRODUCTION}

The European Union currently connects various countries with different economic maturity, size, culture, languages, religions, traditions and history. Its aim is to create an advanced and

Address of the author:

Viera Čihovská

㭋 viera.cihovska@vsemvs.sk competitive economic and monetary union, which can promote in a global world economy. An important task in rendering the Union should therefore be to promote the competitiveness of all its Member States and the individual companies within these states and the formation of a single European market.

With the emergence and gradual enlargement of the EU with more countries a single market was 
formed, creating a strong economic area without internal frontiers in which the free movement of goods, persons, services and capital is secured. Currently, it represents $40 \%$ of world trade and is the largest internal market with fixed terms applicable to all member countries of the European Union. It is a union of 27 states that have their own traditions, language, culture and religion into a single multinational entity where those differences between countries stir and overlap. Such an integrated market requires to apply a specific marketing approach, which must take into account changes in market conditions (for example, different legislative conditions), depending on which country we make business in. The main cause that European marketing emerged was the formation of a single internal market in 1993, which now represents an area with $491,481,700$ inhabitants. A specific feature of the EU market is the fact that the single market, despite the unification of common norms and standards and the effort for a gradual convergence of economic strength of individual countries and regions is still a highly heterogeneous market.

The aim of this project in this context is to bring the formation and content of European marketing as a new concept of analysis and to study a large and heterogeneous European market which brings both opportunities and risks for businesses that want to promote in this fiercely competitive global environment.

\section{THE ORIGIN AND NATURE OF EUROPEAN MARKETING}

European Marketing is a response to the emergence of the large European market by broadening the scope of its examination of the formerly separate markets for a multinational and multicultural market. Extending the application areas of marketing and adapting it to different situations causes that the current marketing is increasingly confronted with the internationalization and globalization of businesses. In relation to the markets that differ by economic, demographic, social and cultural characteristics, the question that arises is how to align customer requirements with the needs for standardization, which enables productivity growth. The answer to these questions is the concept of European marketing as part of a global marketing approach, whose substance and implementation is an object of discussion.

European Marketing presents a new concept of marketing in the European Union with regard to the process of unification and globalization. European Marketing combines a global and a local approach based on the strategy of standardization with regard to cultural conditions and specifications of the European Union. It can be defined as an adaptation of strategies and elements of the marketing mix, i.e. of product, distribution, and pricing and communication policy to the European single market conditions. The main objective of the European Marketing is to correctly define the cultural specificity of the European market and at the same time take into account different cultural conditions in countries and regions of the single European market.

European marketing as a discipline originated in the late seventies and early eighties under the German school of marketing theory in response to the political processes of the single European internal market and the subsequent processes of globalization of the world economy and the growth of international competition. The initial vision for the European market was to create a common market in the European area. Later, after the establishment of the European Community, this idea was transformed into a "European industry for global competition" (Halliburton \& Hunerberg, 2004, p. 245).

McDonald and Harris characterized the European marketing as marketing, similar to international marketing, because it involves different decisions necessary to sell products launched across the country's borders. Borders are barriers that differentiate European marketing from domestic marketing. Of course, EU Member States have lower barriers than non-member countries. Euro area members use the same currency - the euro, which represents zero risk in the exchange rate and a zero cost of monetary transaction. According to the authors, the basis of European marketing is the creation and development of means to achieve legal, economic, social and cultural conditions in European countries, which may be helpful for mutual business transactions (Harris \& McDonald, 2007). 
When comparing the European market with a national market the differences that arise are quite significant. They are not only in competition, multiplicity of product variations, but also in different distribution systems. The European market brings a more competitive fight, but on the other hand, businesses can benefit from economies of scale resulting from the size of the market. It is also contributing to the creation of closer cooperative relations between firms, which may increase the efficiency of research and development activities. Greater efficiency in logistics and distribution is also foreseen in the future. Since there is large number of consumers and business customers in the European market, it is assumed, that there will be more product variations than on the national markets (see table 1).

Table 1. The Intensity of the Relationship between National and European Marketing

\begin{tabular}{|c|l|c|}
\hline National Marketing & \multicolumn{1}{|c|}{ Category } & European Marketing \\
\hline weak & competition & strong \\
\hline high & price discrimination & low \\
\hline low & efficiency of research and development & high \\
\hline low & efficiency in logistics, marketing and distribution & high \\
\hline minimal & product variations & various \\
\hline low & cooperation and coordination & high \\
\hline dispersive & activity configuration & concentrated \\
\hline small & range of benefits & large \\
\hline
\end{tabular}

Source: (Kaynak, 2004, p. 23)

The development of the European market has caused the creation of a new approach to marketing management. The European Union is a very interesting special case in terms of international marketing, because it integrates a comprehensive marketing environment with typical elements of national, supranational and international characteristics. Some economic, legal, political and technological factors of the marketing mix of European Union countries cannot clearly determine whether they are of a national or international nature, since they represent a combination of national and international policies and rules. Changes occurred mainly in the macroeconomic environment, which helped to link internal and international marketing. Euromarketing on the one hand emphasizes the national characteristics of the market, on the other hand, it points to the international aspects of the market. (Table 2).

Table 2. The Comparison of National and International Marketing

\begin{tabular}{|l|l|l|}
\hline \multicolumn{1}{|c|}{ National marketing } & \multicolumn{1}{c|}{ Euromarketing } & \multicolumn{1}{|c|}{$\begin{array}{c}\text { International/global } \\
\text { marketing }\end{array}$} \\
\hline National language & National Language / English & National Language / English \\
\hline No customs & No customs & Customs/ custom fees \\
\hline No border control & No border control & Border controls \\
\hline No export license & No export license & Export license \\
\hline No import license & No import license & Import license \\
\hline Uniform standards/directives & Uniform standards/directives & Different standards/directives \\
\hline Available market information & Available market information & Limited market information \\
\hline Uniform culture & Different cultures & Different cultures \\
\hline Single tax & Base tax & Variable tax \\
\hline Developed means of marketing & Developed means of marketing & Various means of marketing \\
\hline Single currency & Single currency & Several currencies \\
\hline National segmentation & Euro-market segmentation & Extensive segmentation \\
\hline
\end{tabular}

Source: (Kaynak, 2004, p. 22) 
As shown in Table 2, European marketing represents a transitional stage between the internal and international marketing. It has characteristics of internal marketing, along with cultural diversification and globalization. An effective marketing strategy for the European market should be a combination of internal and internationalist marketing approach with a global attitude. A specific feature of European marketing is that it perceives Europe as a clearly geographically defined segment that extends homogeneous in terms of Europe, but different in terms of other global regions. The central concept of European marketing is therefore market segmentation, which uses national boundaries as the basic criteria for its segmentation policy. From the point of view of global marketing, the world performs as one market segment, while European marketing perceives individual European economies as different countries with their national specificities. European market should, in terms of a global marketing strategy, take over at least the part which foresees the use of standardization and uniform marketing methods. The definition of whether the European market is a good place for global marketing and globalization strategy depends on the analysis of macro environment, which from the business perspective can serve as a first step in deciding on euromarketing strategies. Arguments of some authors speaking in favor of a global approach may be reduced to two complementary directions - customer convergence (global consumer or the European consumer) and the efficiency of global products (global product or europroduct) or customer divergence resulting mainly from cultural differences. We agree with those who support a global perspective, and see European marketing as a transition from national to global marketing approach, however, with the emphasize on intercultural marketing approach.

This concept responds to the weaknesses of global marketing approach that does not sufficiently take into account the socio - cultural differences in consumer markets, does not allow a rapid response to the competitive process and can greatly discourage managers in foreign subsidiaries, which are regulated by central decisions of the parent companies. The trend towards intercultural marketing is based on the fact that consumer behavior is strongly influenced by social and cultural factors. Experience shows that the more a country is rich and the more it is advanced, the more different are needs and desires of individual segments. A significant difference between global and intercultural marketing is also that in the case of global marketing the realized products are originally designed for the domestic market, and that all procedures and marketing mix are standardized. Intercultural marketing on the other hand, uses a priori an international approach (Machkova, 2006). A company already at the stage of research and development of new products expects their application on the global market and develops international products (cars, which are easy to assemble according to the needs of the target market). The current marketing trend is based on a maximum effort in the use of standardized procedures, in which a company adapts to local conditions. The intercultural marketing concept is best characterized by the slogan "Think global, act local".

Enterprises applying intercultural marketing take into account the socio-cultural differences of consumers and focuses on a relatively inexpensive adaptation primarily in these following areas:

- Product policy - aims to change products to match local conditions or customer wishes (e. g. Phillips started earning in Japan only after their coffee shrunk to fit into smaller Japanese kitchens and adapted its shavers to better fit smaller Japanese hands). Even big global corporations are now better adapted to local cultural values and traditions instead applying the same approach worldwide (Although McDonald's uses the same basic operating procedures in all restaurants, it adapts its menu to local tastes).

- Brand-name policy - foreign producers use famous domestic brands to manufacture products, they select suitable branded products for the target market. (Nokia modified their mobile phone product line 6100 for every major market).

- Pricing policy - in countries with a low purchasing power, the offer focuses on basic products without any supplements, a smaller consumer package at a lower price, or on offering consumer loans. 
- Distribution policy - foreign trade operators adjust the opening hours of shops according to the local customs of the country, they adapt the assortment structure to the requirements of consumers, they use local delivery systems etc.

- Communication policy - foreign companies adapt advertising and other communication tools to local customs, for example. Sponsoring a favorite sport, charitable activities, performances of local celebrities in commercials etc. (For example, Austria and Italy restricts advertising aimed at children in Saudi Arabia a woman cannot appear in an advertisement). In various European countries, for example, the time devoted to television advertising varies from four hours in France to a total ban in the Nordic countries, where the preferred form of advertising is in the press.

Adapting to every single country is too expensive and therefore European Marketing Management currently emphasizes the concept of socialcultural zones. This concept is based on the assumption that it is possible to identify certain geographical areas with similar socio-cultural characteristics, which enables to use a single marketing approach for several countries.

Basically, it can be compared to an approach of Perry (Halliburton \& Hunerberg, 2004) which says that marketing is a unique phenomenon consisting of exogenous factors that are part of a continuous process of shaping and combining marketing strategies due to changes in local, regional and world development. Although this approach shows some similarities of individual marketing systems, but it also confirms their natural diversity. Euromarketing with regard to the differences would more closely resemble the global than the multinational approach. There is a difference between the multinational marketing and the global approach to marketing. The global approach is looking for commonalities between markets, promotes product homogeneity, image and marketing communication and determines whether a single product or an entire marketing system applies to the world market. In contrast, multinational marketing is looking for the best adaptation of all marketing tools and marketing strategies for each country respectively for each region. Not only many Europeans interpret the
European market as a global market space, but this view is also shared by executives in multinational companies.

European marketing from this point of view consists of a set of theoretical and practical principles of corporate activities on a specific single market of the European Union. These principles are established by extensively harmonized standards of commercial law, consumer protection, competition and a market devoid of protectionist tariff barriers at the borders of the internal markets between the countries members of the EU. Their foundation is based on a special freedom of final consumers, businesses and markets, which are different as a result of the history of different levels of social and economic development of the countries that form the EU and the European common market. Such an integrated market also requires to apply a specific marketing approach. Marketing must take into account the change in market conditions (for example, different legislative conditions), depending on which market we make business. Although the EU provides central business conditions certain powers are left to individual countries (e.g. the sale of genetically modified foods). This means that a company that wants to operate in the long term and be successful in this market must properly adapt its marketing program to the chosen segment in the common market. Gradual removal of barriers between countries and the emergence of a free market created an opportunity for consumers to shop anywhere. From this perspective, the countries forming a common market have become competitors with each other and it is in their interest to provide the best conditions for business and also attract the most customers.

\section{SPECIFICS OF EUROPEAN MARKETING}

One of the key questions in the European marketing is whether market segments may be limited by national borders within Europe, because Europe as a whole is too heterogeneous to act as one large homogenous segment. In this context Lipianska says that the market of the European Union has not been a homogeneous marketing environment for a long time. On the contrary, the EU market is characterized by different 
characteristics both in terms of national and regional. The European Union has created a highly integrated market environment, which consists of various parts, which vary in their differences in political, legal, technological, cultural and economic environments Hence the fact that customer segments are no longer bounded by national borders on the market of the European Union, but have a similarity score in the shopping behavior in different EU countries. Another issue for discussion in the drafting of European marketing is the definition of the character of the segments. When there is an identical segment on a completely different side of the world, it means that one cannot assume any unification of European segments. One solution is to graduate segments based on their exclusivity. Another important condition for segmenting Euromarketing is to define the European Community. Given the emergence of a single large EU market it can be said that Europe is becoming more congruent to the European Union even though there are some exceptions. These include Switzerland, Norway, and the former countries of Yugoslavia which, however, may soon be integrated into the EU. Additional exceptions may be the Ukraine, Belarus, Moldova, which because of their peripheral border between Europe and Asia do not belong to the relevant countries Turkey, however, acts as a specific country, not only because of its market size, but especially its geographic location.

The European Union has undergone many changes since its inception that gradually affect its appearance and therefore marketing activities. These changes have fundamentally affected all parts of the European Union, particularly the actual business environment in Europe. European Marketing according to the European Commission is now determined by the following conditions (EuropeanCommision, 1997):

- The creation of a common European market has caused changes in conditions for the implementation of marketing strategy.

- The largest differences occur in the patterns of consumption and consumer behavior.

- The market remains inconsistent.

- A new approach to market segmentation is needed.

- The competitive environment is changing.
- The unification of purchasing condition.

- The importance of retail distribution systems is growing.

- The development of self-service forms of selling.

- The increase in the number of large business units.

- The development of retail without retail space.

It is known that marketing activities involve a complex process that is carried out in order to develop and provide customers with the desired goods and services. At the core of these activities are marketing research of environmental factors, identification and characterization of species and product lines preferred by different types of customers, market testing of products, determining the market price of products in order to maximize results and profits, providing relevant and accurate information to customers on all product properties, influencing the buying behavior of consumers. These activities include the distribution and after purchase service and maintenance designed to enhance the level of future services. Despite the fact that all listed activities are in accordance with the general rules of marketing, marketing in an international environment and thus the marketing in the European Union requires a different approach from those which are customary for individual national markets. In this case, it is important to assess the factors that bind to the political, economic, legal and cultural environment that differ marketing in the European context from marketing on the domestic market or in a nonEuropean international environment.

European Marketing has some typical characteristics and features. What makes it different from for example, the U.S. marketing, whose primary objective is to weaken competition and mainly practice so called battle-marketing, is that its priority goal is to grab the attention of customers, know their needs and wishes the best and adapt to them.

European Union legislation, distribution systems and the entire economic growth of their countries is leading towards the harmonization of the European market. The best examples of this are young people who prefer the same brand clothing, have a similar lifestyle, and listen to the same 
music. Also, managers have a similar way of life and rhythm. On the other hand, we see how the regional traditions mix and mingle. For example, drinking beer, which is typical of northern Europe, has increased drastically in the southern hemisphere in recent years, and vice versa. From this perspective, a marketing concept can be understood as an effort to increase the likelihood of business success and to achieve marketing goals on the EU market. It is thus an approach that does not want to leave the outcome of the business only to chance, but it is rather systematically trying to create maximum favorable conditions and assumptions with the most diverse procedures and possibly doing that by noticing what customers in the European Union want, what they prefer, and what their wishes, desires and needs are.

The current marketing must therefore give priority to the following areas:

- A thorough knowledge of the market and the environment - it is the environment in which the company wants to operate by collecting the required number of pertinent and relevant information from primary and secondary sources. If the company wants to do business in the single European market, it has to focus on the acquisition of information: general information about the country, specifications peculiar to the relevant market, market growth, profit potential, market size etc. The basis for analyzing the opportunities offered by the country consists of market research based on the information above. Each environment is characterized by different economic, cultural and legislative conditions. Cultural conditions are particularly important for marketing analysis, because different hobbies, tastes and lifestyle affect different consumer behavior.

- Market segmentation - Market segmentation is one of the essential elements of a successful marketing. Customers differ in their interests, needs, wants, income, residence, etc.

- Keeping your customer - customer retention is a very important element. A prerequisite is to create a positive and effective relationship with customers through an understanding of its current and future needs and wishes, creating an offer of a product or a service that will satisfy him. Customer satisfaction is influenced by several aspects: product (the design and processing, design), sales activities (marketing communication), aftersales activities (servicing, warranty, spare parts), corporate culture at all level

- Competition analysis - in terms of price, quality and innovation of product, availability of products, services, servicing, etc.

Creating a universal solution for all European products is impossible. Even within the same industry European segments and regional segments can coexist. For example, on the beer market there is a small amount of europroducts, one of which is Heineken, which in Germany coexists with a thousand other different brewing products. Any efforts to standardize in a higher level could be, due to the existing differences between European countries, considerably inappropriate.

Marketing focused on European markets is therefore based on the application of three approaches:

- global approach - useful in situations with an identifiability of universal consumer characteristics on individual national European markets (e.g. trends in rational diet),

- local approach - useful in identifying different patterns in consumer behavior in local markets, different economic and social levels of the different markets (e.g. differences in GDP between EU members,

- regional approach - useful in expanding to markets with similar economic, cultural, historical or geographical characteristics (e.g. Scandinavian countries, German speaking countries, etc.)

Joining the three approaches helps to use a strategy of standardization while taking into account cultural conditions and specifics of the EU countries. The future of European marketing is directed to complementarity and cooperation of the entire distribution chain for the consumer.

European drivers may, on the demand side, lead to the convergence of characteristics of European consumers, and on the supply side, to the standardization of European marketing strategy. Standardized marketing can entail conformal side 
effects on the supply side, supported by cost or price factors that will determine the intensity of euro-marketing convergence structure. European
- versus global marketing structure is shown closer on the chart 2.

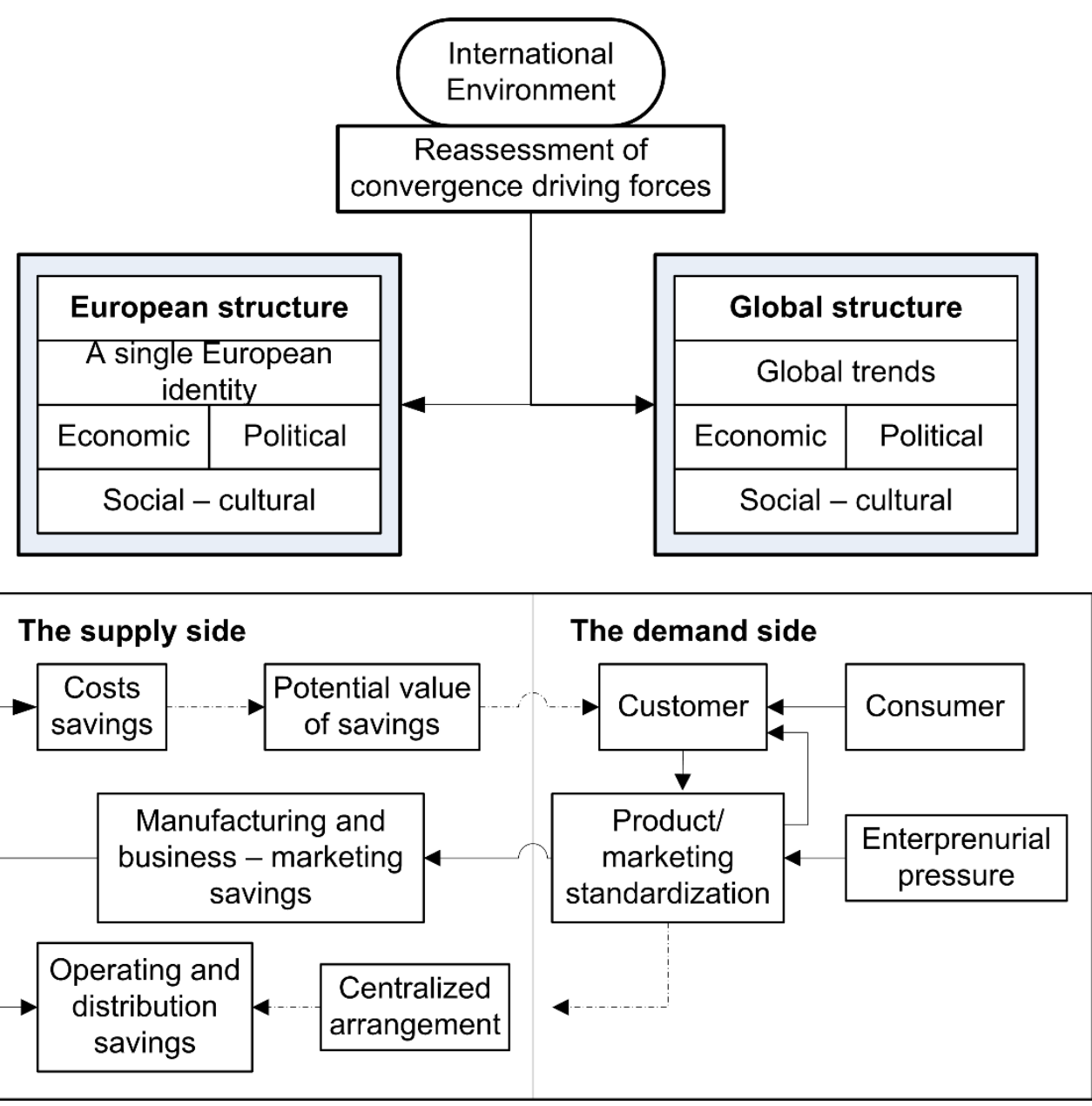

Chart 2: Structure of European Marketing

Source: (Harris \& McDonald, 2007, p. 12)

In recent years, predictions of European divergence recede into the background, while views on European conformity are still pronounced. This is reflected especially on the supply side, where the effects caused by European integration are crucial to the homogeneity of the market. These predictions also indirectly support the convergence on the demand side. In the case that these premises are valid, then corporate decisions about the right market strongly influence strategic options, which may lead to certain forms euro-segmentation. From the perspective of a longer time horizon, it may be a transitional phase leading to a full global access.

\section{CONCLUSION}

European Marketing therefore has much in common with the international marketing and especially in the management and decisionmaking on the implementation of the products (goods and services and their combinations) abroad. The borders between states become barriers which can be considered as a fundamental difference between the European and international marketing. Although the intensity of these barriers varies within individual EU countries, their common interests are marketing activities. According to Harris and McDonald, the main difference between the European and internal marketing is based on the cross-border trade barriers. These barriers vary according to 
whether the country is a part of the EU and the Eurozone. Countries outside Europe seeking to enter the market are exposed to a complicated marketing environment, and while there are similarities in the economic and legal environment, there are also big differences in cultural and social fields. European Marketing can therefore be described as a special type of international marketing with some common features with the domestic marketing of those countries, among which are minimal differences in the legal, economic, social and cultural fields. This means that the founding countries of the EU and the eurozone countries have, among all EU countries, the lowest level of political and economic barriers. Many marketing experts expect that the single European market will promote the convergence of tastes of European consumers and promote a "European consumers". Convergence of values, lifestyles, beliefs, habits and tastes does not mean that their needs will converge as well. They may vary on individual national markets, as well as the purchasing power and the consumption habits of buyers differ. Europe as a mixture of different cultures and systems thus represents marketing opportunities for businesses both in the field of production and in the filled of trade. While it is possible to combine the social and demographic characteristics and marketing strategies of firms producing consumer products to approximate the styles of individual European countries in the new global economy, diversity will be as important as the convergence point. Businesses should therefore identify regional, national and local specificities and develop appropriate marketing strategies which take account of this diversity. Pan-European strategies may be cost-effective in places where consumers have similar cultural values and homogeneous tastes concerning a particular product or service. Standard marketing program can be used for example in the field of luxury products (such as jewelry, Rolex watches, sports cars, etc.), which requires a small number of like-minded customers, or in the field of fashion articles that young people buy in all countries (global approach). Social and cultural characteristics, however, are significantly different across Europe, and this requires an adaptation of marketing strategies, depending on the regional markets of the EU. It can therefore be said that Europe is still far from becoming a single internal market for European companies, but also far from becoming a single market for foreign companies outside Europe.

\section{WORKS CITED}

EuropeanCommision. (1997). Euromarketing. Bruxeles : Office for oficial publication of the european commuties.

Halliburton, C., \& Hunerberg, R. (2004). Pan-European Marketing. London: TheHaworth Press.

Harris, P., \& McDonald, F. (2007). European business and marketing. London: Sagepublication.

Kaynak, E. (2004). Euromarketing. London: TheHaworth Press.

Machkova, H. (2006). Medzinárodní marketing. Praha: GradaPublishing.

\section{Acknowledgement}

The paper was written within the work on the project KEGA No.1/0046/14 "Euromarketing - factors and determinants of the single European market", at the Faculty of Commerce, University of

Economics in Bratislava".

Received for publication:

Revision received:

Accepted for publication:
30.01 .2014

28.05.2014

18.06.2014 


\section{How to cite this article?}

Style - APA Sixth Edition:

Čihovska, V. (2014, 07 15). European marketing - concept for efficient exchange of the single market of the European Union. (Z. Čekerevac, Ed.) MEST Journal, 2(2), 32-41. doi:10.12709/mest.02.02.02.04

Style - Chicago Fifteenth Edition:

Čihovska, Viera. 2014. "European marketing - concept for efficient exchange of the single market of the European Union." Edited by Zoran Čekerevac. MEST Journal (MESTE) 2 (2): 32-41. doi:10.12709/mest.02.02.02.04.

Style - GOST Name Sort:

Čihovska Viera European marketing - concept for efficient exchange of the single market of the European Union [Journal] // MEST Journal / ed. Čekerevac Zoran. - Belgrade : MESTE, 07 15, 2014. 2 : Vol. 2. - pp. 32-41.

Style - Harvard Anglia:

Čihovska, V., 2014. European marketing - concept for efficient exchange of the single market of the European Union. MEST Journal, 15 07, 2(2), pp. 32-41.

Style - ISO 690 Numerical Reference:

European marketing - concept for efficient exchange of the single market of the European Union. Čihovska, Viera. [ed.] Zoran Čekerevac. 2, Belgrade : MESTE, 07 15, 2014, MEST Journal, Vol. 2, pp. 32-41. 